\title{
The Rubber Glove Osteotomy Method for Soft Tissue Retraction in Digital Replantation
}

\author{
Georgios Pafitanis, MD ${ }^{1,2 *}$; Reza Alamouti, FRCS (Plast)'; Dariush Nikkhah, FRCS (Plast)'; \\ Mohammed Shibu, FRCS (Plast) ${ }^{1}$
}

' Department of Plastic and Reconstructive Surgery, The Royal London Hospital, Barts Health NHS Trust, London, UK

${ }^{2}$ Group for Academic Plastic Surgery, Queen Mary University of London, London, UK

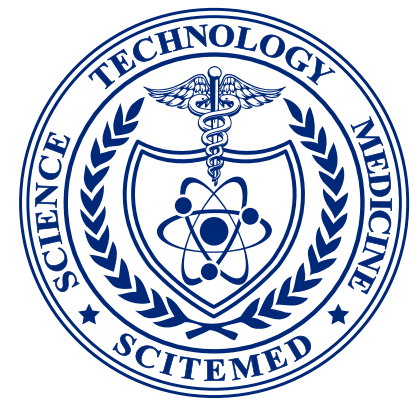

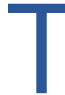

he use of rubber gloves to assist surgical tasks in hand surgery has been reported previously [1]. Surgical rubber glove is a cheap tool that could be used as a T-ring tourniquet or as a retraction tool while performing sharp debridement or osteotomy. In trans-phalangeal finger replantation, osteotomy and bone osteosynthesis are crucial to achieve optimal possible functional outcomes. A $10 \times 10$ centimeters piece of rubber surgical glove with a small 2 millimeters puncture hole is cut with a No. 11 surgical blade. After periosteal elevation is performed, the amputated phalanx, distal or proximal, is passed through and a mosquito or babcock is used to provide stability during manipulation [2]. While draping the digital soft tissues under the rubber glove, the line of osteotomy is clearly visualised (Figure 1). The saw is then used to safely and effectively cut through with precision and without the interference of soft tissue during osteotomy. In finger replantation, tissue retraction is a key step in achieving optimal osteosynthesis without the intrusion of the surrounding soft tissues (Figure 2) [3]. It's a simple and cheap technique and allows better grip with a regular glove to fully enclose all soft tissues to prevent iatrogenic injury during osteotomy [1,2].

\section{Article Information}

* Correspondence: Georgios Pafitanis, MD

Group for Academic Plastic Surgery, Queen Mary University of London, 4 Newark Street, Whitechapel, E12AT, London, UK.

Email: g.pafitanis@qmul.ac.uk

The first and second authors contributed equally to this work.

Received: Apr. 12, 2018; Accepted: May 22, 2017; Published: Jul. 16, 2018

DOI: 10.24983/scitemed.paciv.2018.00070

Copyright $\odot 2018$ The Author(s). This is an open-access article distributed under the terms of the Creative Commons Attribution 4.0 International License (CC-BY).

\section{Funding: None}

Conflict of Interest: None

\section{References}

1. Reissis D, Nikkhah D, Bayne D. Safer and precise replant osteosynthesis with the T-Ring digital tourniquet. J Reconstr Microsurg Open 2016;1(1):71-72.

2. Nikkhah D, Sadr AH, Murugesan L, Konczalik W, Rodrigues J. Cross-clamping of bony stumps in preparation for osteosynthesis in digital replantation. Microsurgery 2017;37(4):356-357.

3. Morrison WA, McCombe D. Digital replantation. Hand Clin 2007;23(1):112.

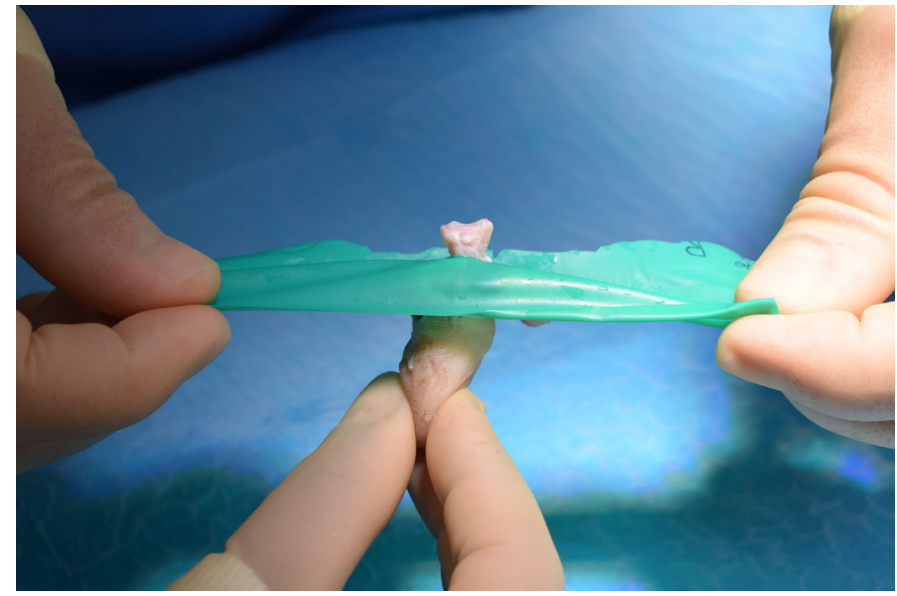

Figure 1. The rubber glove method demonstrating the amputated digital bone passing through the tight hole while all soft tissues have been retracted.

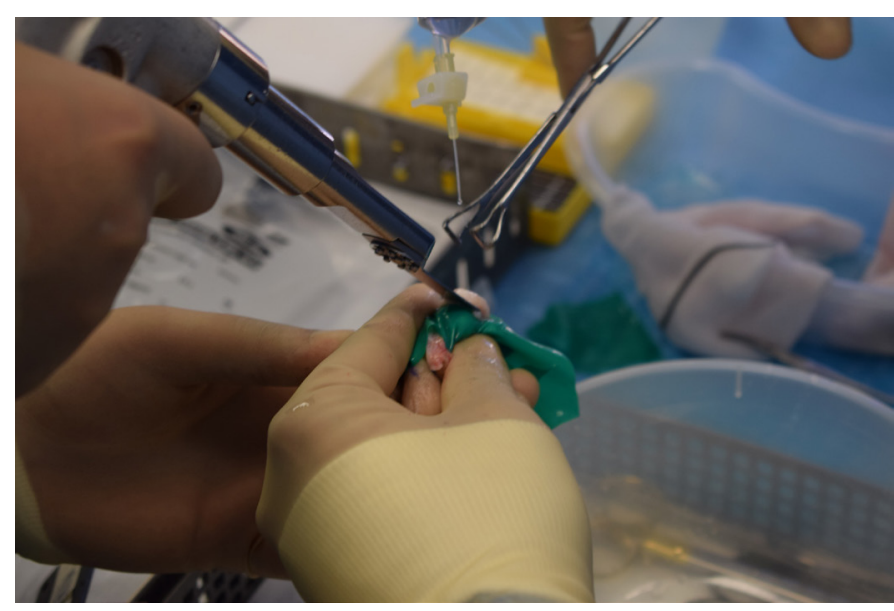

Figure 2. The rubber glove assisting good grip during osteotomy with an oscillating saw. 